\title{
A QUÍMICA NA EDUCAÇÃO DA PRINCESA ISABEL
}

\section{Carlos A. L. Filgueiras}

Departamento de Química Inorgânica, Instituto de Química, Universidade Federal do Rio de Janeiro, CP 68563, 21945-970 Rio de Janeiro - RJ

Recebido em 29/4/03; aceito em 26/9/03

\begin{abstract}
CHEMISTRY IN PRINCESS ISABEL'S EDUCATION. The private archive of the Brazilian Imperial Family holds a wealth of little known documents about the education of the daughters of Emperor D. Pedro II, especially of the eldest, Isabel, Princess Imperial. Science, particularly chemistry, for which her father had a particular fondness, occupied an important place in the girl's education. The study of these documents sheds a new light on the contrast between female education in the country in general, during most of the $19^{\text {th }}$ century, and the careful upbringing envisaged by the Emperor for his future successor.
\end{abstract}

Keywords: Princess Isabel's Education; Education in the $19^{\text {th }}$ Century; Female Education in Brazil.

Em 15 de outubro de 1827 o Imperador D. Pedro I sancionou uma lei que mandava, em seu artigo primeiro, criar escolas de primeiras letras em todas as cidades, vilas e lugares mais populosos do Império. A mesma lei, no artigo 11, dizia que haverão (sic) escolas de meninas nas cidades e vilas mais populosas, em que os Presidentes em Conselho julgarem necessário este estabelecimento. O parágrafo seguinte delimitava cuidadosamente os limites da educação a ser dada às meninas que a ela tivessem acesso, com exclusão das noções de geometria e limitando a instrução de aritmética só às quatro operações; ensinarão também as prendas que servem à economia doméstica ${ }^{1}$. A educação pública ministrada aos jovens brasileiros, apesar de exígua, ainda era mais limitada quando se tratava das poucas meninas a conseguir acesso aos bancos escolares. Ainda assim, frequientemente os pais tiravam as filhas da escola mal elas aprendiam a costurar, evitando que aprendessem a ler, escrever e contar $^{2}$.

O Ato Adicional à Constituição do Império, em 1834, viria a atribuir às províncias a responsabilidade da educação pública. Essa descentralização, naquele momento histórico, teve como conseqüência condenar as províncias mais afastadas da capital do Império a uma situação de abandono educacional, piorando uma situação que já era ruim³ ${ }^{3}$

A educação particular feminina pouco diferia do quadro da educação pública. Por isso o Colégio Augusto, fundado no Rio de Janeiro em 1838, por Nísia Floresta, dividiu opiniões e causou polêmicas, ao instituir uma educação feminina completamente inusitada para aquela sociedade. Nísia Floresta (1809-1885) nasceu no Rio Grande do Norte, na cidade que hoje tem seu nome. Depois de viver em vários pontos do país, estabeleceu-se, já viúva e com um casal de filhos, no Rio de Janeiro, inaugurando o colégio para moças com o nome de seu falecido marido. Seu nome de batismo, Dionísia Gonçalves Pinto, já se tinha transformado em Nísia Floresta Brasileira Augusta, como passou a se assinar ${ }^{4}$. Além de seu pioneirismo na educação feminina, Nísia Floresta tornou-se muito conhecida por sua associação com Augusto Comte, de quem se tornou discípula e amiga em Paris, de 1851 até a morte do fundador do positivismo, em 1857. As várias publicações que escreveu espelham suas idéias educacionais, sobretudo no tocante à educação das mulheres, e a influência recebida do filósofo francês. O livro mais famoso por ela dado

*e-mail: calf@iq.ufrj.br à luz é o Opúsculo Humanitário, coletânea de 63 artigos publicados anteriormente em jornais do Rio de Janeiro. No Opúsculo a autora fustiga a instituição da escravidão assim como o estado de inferioridade em que eram mantidas as mulheres na sociedade brasileira. Ao defender o livre acesso das mulheres ao mercado de trabalho diz: Se se instituísse uma classe pública de operárias em toda sorte de trabalhos, oferecer-se-ia a uma parte das famílias desvalidas do Brasil não somente um meio seguro de as livrar da miséria, mas ainda de habilitá-las para um futuro que não está longe . $^{5}$

O Colégio Augusto de Nísia Floresta funcionou no Rio de Janeiro durante 17 anos. Lá se ensinavam várias línguas, como o francês, o inglês e o italiano, além da geografia e a história, bem como a educação física. Ela também condenava o uso do espartilho e limitava o número de alunas a poucas por turma, como garantia da qualidade do ensino ${ }^{4}$. A sociedade conservadora não poupava farpas a Nísia ao ver sua audácia de fazer meninas "invadir" o universo masculino. O jornal carioca $O$ Mercantil escrevia ferinamente em 1847: trabalhos de língua não faltaram: os de agulha ficaram no escuro. Os maridos precisam de mulher que trabalhe mais e fale menos ${ }^{5}$. Opinião oposta foi a do Núncio Apostólico, Monsenhor Giacomo Bedini, ao assistir embevecido os exames anuais de línguas e literaturas estrangeiras, quando foi saudado em italiano e ouviu as alunas a declamar versos de autores italianos e latinos ${ }^{6}$.

O colégio de Nísia Floresta foi fundado contemporaneamente com o Colégio Pedro II, exclusivamente para rapazes, que era um padrão de excelência e sempre mereceu toda a atenção do próprio monarca, que freqüentemente o visitava para assistir e mesmo participar de exames e concursos. Um diploma do Colégio Pedro II era praticamente uma garantia de êxito profissional.

Apenas um colégio privado ensinava ciências a moças. Ele era dirigido por uma professora inglesa, Mrs. Hitchings, e lecionava Astronomia, Botânica, Física Elementar e uso dos globos. Curiosamente, quando se menciona o ensino de História nos colégios, é sempre a História Antiga e Moderna, nenhum deles tratando da História do Brasil ${ }^{7}$.

O Brasil de meados do século 19 era, segundo já se disse, uma ilha de letrados num mar de analfabetos. Em 1872 apenas 18,56\% da população era alfabetizada, dos quais $23,43 \%$ eram homens e $13,43 \%$ mulheres. Entre os escravos o analfabetismo era praticamente total, chegando a 99,9\% . Até o fim do Império só havia sete escolas superiores no país: as Faculdades de Direito de São Paulo e Recife 
(1828), as de Medicina de Salvador e do Rio (1808), a Escola Politécnica do Rio de Janeiro (1874, embora remontando a 1792 com outros nomes), a Faculdade de Farmácia de Ouro Preto (1839) e a Escola de Minas nessa mesma cidade (1876).

É interessante notar a formação da elite política do império, que variou bastante com o tempo: com formação em ciências, houve 20,5\% dos ministros do período 1822-1831; 13,3\% em 1831-1840; $5,0 \%$ em $1840-1853 ; 2,1 \%$ em $1853-1871$ e $0,0 \%$ nos anos que se seguiram, 1871-1889, até o fim do regime monárquico9 ${ }^{9}$ Entre os deputados à Constituinte de 1823, 34 tinham um diploma universitário em ciências, às vezes mais de um diploma. Por ciências estão aqui compreendidas a Matemática, a Filosofia Natural e a Medicina. Doze daqueles deputados eram formados em Matemática e Filosofia Natural, 9 em Matemática, 5 em Filosofia Natural, 3 em Medicina, 3 em Medicina e Matemática, e 3 em Matemática, Filosofia e Medicina. Dos 55 deputados constituintes com curso superior, 21 eram bacharéis em Direito e os outros 34 compreendiam o grupo com formação científica ${ }^{10}$.

Este é o pano de fundo contra o qual se estudará a educação planejada e executada minuciosamente pelo Imperador D. Pedro II para suas filhas Isabel e Leopoldina, sobretudo a mais velha, herdeira presuntiva da coroa. $\mathrm{O}$ contraste com o que se observava na sociedade brasileira é marcante, e reflete a predileção do imperador pelas ciências, que ele passou a incutir, aparentemente com êxito, em Isabel. O interesse do Imperador pelas ciências como apanágio intelectual é amplamente conhecido ${ }^{11}$, e pode ser constatado visualmente por muitas representações em que ele se faz retratar cercado de ícones da ciência.

Não havia no Império sequer a permissão legal para que mulheres freqüentassem cursos superiores. Por isso, a primeira brasileira a se formar em Medicina, a carioca Maria Augusta Generoso Estrela, teve que realizar seu curso em Nova Iorque, diplomando-se pelo New York Medical College and Hospital for Women em 1881, com uma tese sobre Dermatologia, com a distinção de ter sido selecionada

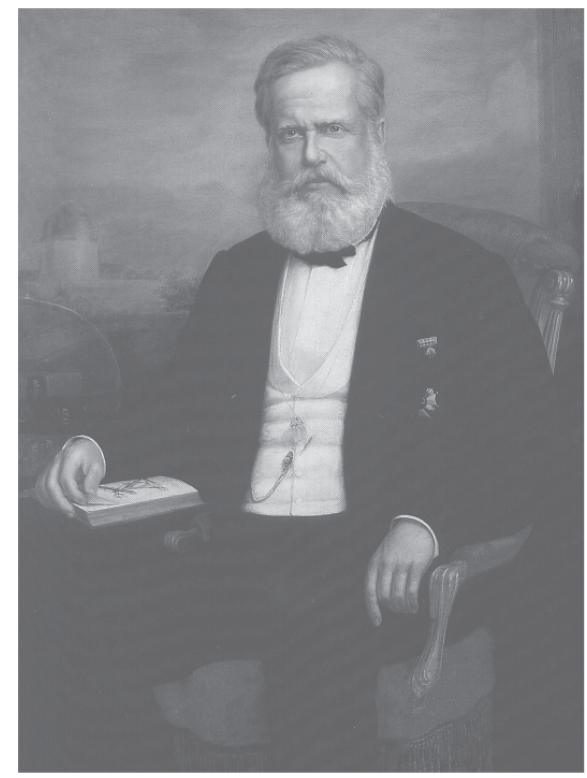

Figura 1. Retrato de D. Pedro II, por Delfim da Câmara (1875). O imperador está cercado de ícones da ciência: sua mão direita segura um livro onde se vê a representação de um telescópio; à frente do que parece ser um globo celeste estão três livros, perfeitamente visíveis no original a óleo, com os nomes Arago, Kepler e Halley escritos nas lombadas. Ao fundo, vê-se a cúpula de um telescópio do Imperial Observatório do Morro do Castelo. Museu Histórico Nacional para oradora da turma. Durante seus estudos Maria Augusta perdera o pai, o que levou o Imperador, em janeiro de 1878, a conceder-lhe uma pensão anual de 1:500\$000. Esta foi a primeira bolsa de estudos recebida por uma brasileira para a realização de estudos universitários. A partir de 19 de abril de 1879, com a Reforma Leôncio de Carvalho, conferiu-se a liberdade e o direito da mulher de freqüentar cursos das Faculdades, de obter um título acadêmico. Em conseqüência da nova lei, matriculou-se em 1884 na Faculdade de Medicina do Rio de Janeiro a jovem estudante gaúcha Rita Lobato Velho Lopes, a primeira brasileira a colar grau num curso superior no Brasil, o que ocorreria em 10 de dezembro de $1887^{12}$.

O Imperador D. Pedro II teve quatro filhos: D. Afonso (18451847), D. Isabel Cristina (1846-1921), D. Leopoldina Teresa (18471871) e D. Pedro Afonso (1848-1850). Com as mortes prematuras dos dois varões, Isabel tornou-se a herdeira oficial do trono ao completar 14 anos, fazendo o juramento solene à Constituição do Império perante o Senado Imperial. A partir daí passou a ter o título de Princesa Imperial ${ }^{13}$.

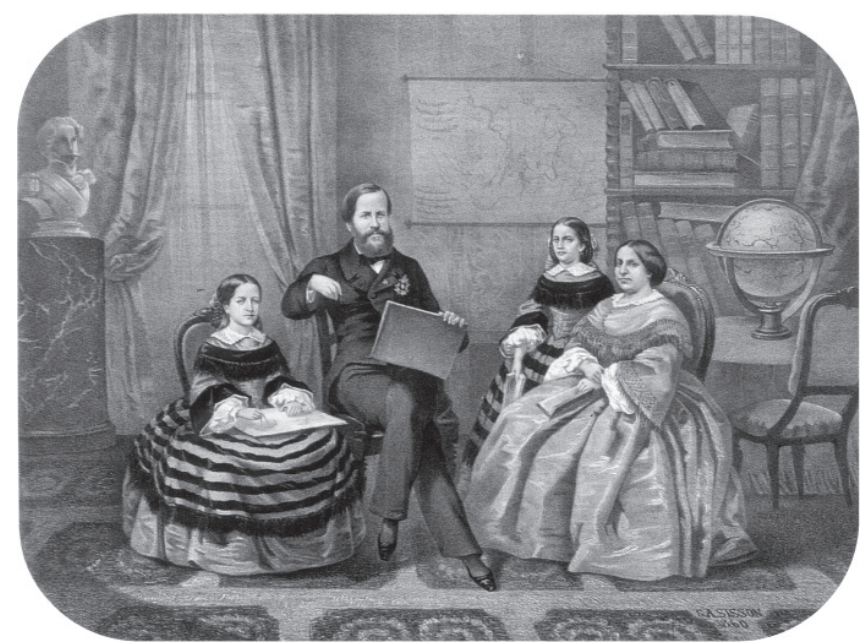

Figura 2. A Família Imperial na Biblioteca do Imperador, em litografia de Sisson, de 1860. Os quatro membros da família foram representados segurando um livro ou objeto de estudo. Arquivo do Museu Imperial

Desde cedo o Imperador se preocupava com a educação das filhas. Em 1853 ele tentou, em vão, fazer com que sua madrasta, a Imperatriz viúva D. Amélia, voltasse de Portugal para assumir o encargo de preceptora das princesas. Com a recusa da ex-Imperatriz, D. Amélia é então encarregada pelo enteado de procurar na Europa alguém com as seguintes características: alemã, católica romana e religiosa, viúva e sem filhos, melhor maior de 40 anos, sem pretensões..., sem interesses na Europa, falando bem as línguas mais usadas, entendendo o português ou que venha depois de saber alguma coisa dele, para não estar sem ocupação quando aqui chegar, tendo gênio dócil e maneiras delicadas, e conhecendo perfeitamente os diversos misteres em que as senhoras passam as suas horas vagas. Quanto à instrução não exijo muito porque minhas filhas hão de ter mestres $^{14}$. O rígido figurino desenhado pelo Imperador para a preceptora desejada resultou em nada.

Depois de muitas tentativas infrutíferas, foi a irmã do Imperador, D. Francisca, Princesa de Joinville, que lhe sugeriu de Paris, onde vivia, que ele convidasse para o cargo a então Viscondessa, mais tarde Condessa de Barral, D. Luísa Margarida Portugal de Barros. Após uma longa negociação, a Barral aceitou e assumiu suas funções em setembro de 1856, quando Isabel contava 10 anos e sua irmã $9^{15}$. A educação formal das duas princesas prosseguiu até o final de 1864, quando ambas se casaram. 
O regime de estudos das princesas era de uma severidade impressionante. Elas tinham aulas 6 dias por semana, das $7 \mathrm{~h}$ da manhã às $21 \mathrm{~h} 30 \mathrm{~m}$, com pouquíssimos intervalos para recreação. $O$ próprio Imperador determinou: as visitas que procurarem as Princesas serão recebidas unicamente aos domingos, nas festas de guarda e nacionais, nos dias de seus anos, nos dos nossos, nos de seus nomes e nossos, e em qualquer outra ocasião que eu determinar - à exceção dos criados de honra e de serviço. Só haveráférias em Petrópolis, onde talvez seja alterada a distribuição do tempo ${ }^{16}$. O currículo compreendia cerca de duas dezenas de matérias, entre as quais português e sua literatura, francês, inglês, italiano, alemão, latim (cujo professor era às vezes o próprio imperador), grego, álgebra, geometria, química, física, botânica, várias disciplinas de história, divididas por país e por época, cosmografia, desenho e pintura, piano, filosofia, geografia, economia política, retórica, zoologia, mineralogia, geologia, etc. Boa parte das aulas era dada em francês, assim como esta era a língua em que eram redigidos os horários das aulas e os boletins escolares.

A respeito do rigor da educação de suas filhas escreveu o Imperador: o caráter de qualquer das Princesas deve ser formado tal como convém a Senhoras que poderão ter que dirigir o governo constitucional de um Império como o Brasil. A instrução não deve diferir da que se dá aos homens, combinada com a do outro sexo: mas de modo que não sofra a primeira. Convirá conformar-se, quando for de proveito, aos regulamentos da instrução pública primária e secundária. Poderá impor castigos, e quando forem leves, sem meu conhecimento prévio, devendo minhas filhas não saber [ilegível] que o tenho, quando isto não for conveniente, sendo o maior deles a reclusão em um dos quartos dos respectivos aposentos, assim como representar-nos, mesmo perante nossas filhas, sobre a justiça da concessão de algum prêmio ${ }^{17}$. A tudo isso deveria presidir, como supervisora, a preceptora contratada, a Condessa de Barral.

À insinuação preconceituosa de que estava proporcionando a suas filhas uma educação de homem, especialmente no caso de Isabel, apressou-se a escrever-lhe de Paris sua irmã D. Francisca, Princesa de Joinville: acho que fazes bem de dar uma educação de homem a sua filha mais velha, sobretudo que é provável que seja quem venha a governar o país, o que espero seja o mais tarde possível ${ }^{18}$. Apesar disso, D. Francisca achava que o regime de estudos idealizado por seu irmão para as filhas era por demais draconiano e lhe escreveu em 1858: Toma bem sentido de não as cansar muito e que lhes não falte recreação no meio do trabalho. Quatro anos depois, insistia ainda D. Francisca: Temo bem não cansares demais a inteligência. Espero que [Isabel] tenha horas de passeio e alguns intervalos entre as lições para que possa se descansar. Isso é muito importante para a saúde, que sem ela nada é possível fazer-se de verdadeiro trabalho intelectual ${ }^{19}$.

O Imperador, todavia, confidenciou a seu diário: o estudo, a leitura e a educação de minhas filhas, que amo extremadamente, [são] meus principais divertimentos ${ }^{20}$.

Vários professores lecionaram para as princesas: entre estes, podem-se citar Cândido Batista de Oliveira, de Geometria, Francisco de Paula Cândido, de Física, Cândido José de Araújo Viana, Visconde (em 1854) e Marquês (a partir de 1872) de Sapucaí, de Literatura, que havia também ensinado ao imperador, Guilherme Schuch de Capanema, de Mineralogia e Geologia, Freire Alemão, de Retórica, e vários outros. Os fotógrafos Revert Henri Klumb e Marc Ferrez lecionaram Fotografia. Francisco Ferreira de Abreu, médico pela Faculdade de Medicina do Rio de Janeiro, doutor pela Universidade de Paris e futuro Barão de Teresópolis era médico da Imperial Câmara e lente de Medicina Legal na Faculdade de Medicina do Rio de Janeiro. Ferreira de Abreu foi professor de Física e Química das princesas $^{21}$. Poder-se-ia cogitar se aqui também entraria o nome de Alexandre Antônio Vandelli, filho do antigo introdutor da Química moderna na Universidade de Coimbra e genro de José Bonifácio de Andrada e Silva. Vandelli havia sido professor de ciências do próprio D. Pedro II. À época de que trata o presente relato, Vandelli já era homem idoso, vindo a falecer em 1859, quando Isabel só contava 13 anos. Portanto sua contribuição para a educação das princesas só pode ter ocorrido quando elas eram ainda muito jovens.

O Arquivo Grão Pará, em Petrópolis, de propriedade da Família Imperial, conserva uma grande quantidade de documentos relativos à educação das princesas, principalmente Isabel. Esses documentos, embora tratem de todos os assuntos, evidenciam como foi importante a formação científica que o pai fez questão de proporcionar à herdeira. É bastante curioso também como a Química se faz presente de forma maciça nessa documentação, superando o volume de dados consagrados a outras ciências.

A Família Imperial morava em São Cristóvão e tinha o hábito de freqüentar a Igreja da Glória para a missa dominical. O tempo do longo trajeto deveria ser bem utilizado, de acordo com o programa

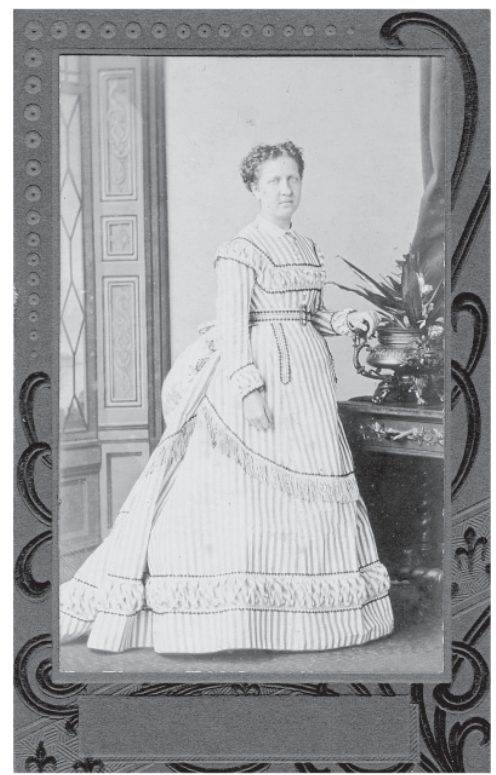

Figura 3. A Princesa Isabel adolescente. Foto do Arquivo do Museu Imperial

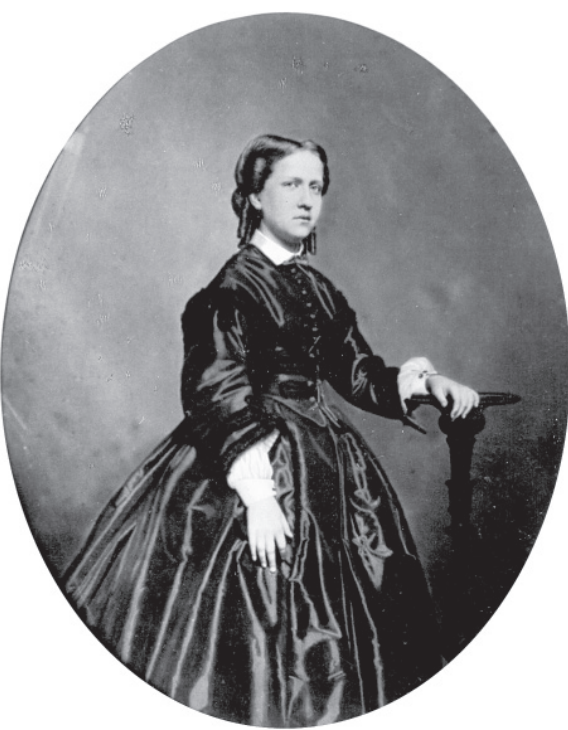

Figura 4. A Princesa Leopoldina, filha caçula do Imperador. Foto do Arquivo do Museu Imperial 
estabelecido. Como se o rigor do regime de estudos não bastasse, lêse num bilhete a Isabel, em francês: Missa na Glória. O estudo do Evangelho pode fazer-se na carruagem ${ }^{22}$.

As princesas não tinham permissão para perambular pelo Palácio da Quinta da Boa Vista e ir ter com o pai. Por isso, sua comunicação era feita por meio de bilhetes, respondidos pelo imperador no mesmo pedaço de papel. Alguns desses bilhetes são bastante saboro$\operatorname{sos}^{22}$ :

1, sem data: Papai, mande-me se puder o caderno às 11 e meia para eu poder continuar a tradução. $I$. $C$.

Não posso. Se não acabou acabe, que já teve tempo para tê-lo feito. 2, sem data: Posso ir passear? O tempo está bom. I. C.

Vá passear se não tirar tempo ao estudo.

3, sem data, contendo uma lista de 10 compostos químicos:

\section{Terra podre}

álcool

collódion

iodure de potassium

azotate de prata

acido pyrogallique

acido acetico cristalisavel

hyposulfito de soda

chloruro de prata

chloruro de ouro

Papai, se me quiser fazer um grande favor peça ao Silveira que procure isto para nós tirarmos vistas d'aqui do palacio. Se nós pudermos, o que acho que sim. Não se ria de mim. I. C.

Todos os documentos citados aqui vão até pouco antes do casamento de Isabel, em outubro de 1864, aos 18 anos de idade, quando cessou sua educação formal. O último bilhete acima é interessante, por mostrar o interesse da jovem princesa pela fotografia, inclusive pelos assuntos técnicos da revelação. O Imperador sempre foi um entusiasta da fotografia e parece ter transmitido seu interesse à filha.

Há muitos textos escritos cuidadosamente na letra caprichada de Isabel, assim como outros em rascunhos de leitura mais difícil. Num longo texto sobre filosofia, por exemplo, escreve (provavelmente copia) Isabel: Bacon e Descartes são geralmente reputados os principais reformadores da filosofia nos tempos modernos: ambos clamam contra o método embaraçado e estéril, que era autorizado nas escolas, e pretenderam substituir-lhe a observação da natureza, e a evidência das idéias da razão. Em contraposição das categorias e das regras silogísticas, que faziam a Lógica ou Filosofia instrumental nos livros de Aristóteles, Bacon escreveu o seu Novum Organum, que fez a primeira parte da Instauratio Magna; e nele recomendou o método de interpretar a natureza, banindo as antecipações pelo emprego da legítima indução, cujos preceitos coligiu e divulgou em aforismos: mas foi exagerado contra o bom uso do método dedutivo.

Descartes, porém, fazia consistir o critério da verdade nas idéias claras, e aconselhava que se tivesse em dúvida tudo quanto não se pudesse reduzir a princípios evidentes, mas ele mesmo perdeu-se na aplicação desta regra, quando para descobrir a primeira verdade clara, tentou uma dúvida universal, da qual, se acaso salva a ciência, não salva por certo a crença do senso comum; e parece assentar a ciência sobre uma base estreita quando a pretende fundar sobre o Cogito ergo sum ${ }^{22}$.

Um outro trecho das lições copiadas por ela diz respeito aos silogismos, dos quais pode-se extrair este exemplo:

Toda perfeição do espírito é um bem real:

Ora, a ciência é perfeição do espírito:

Logo, a ciência é um bem real ${ }^{22}$.

Nas notas ao final deste artigo são reproduzidos alguns horários de aulas e um dos boletins de notas de Isabel. As notas são dadas por conceitos, como B (bien, bem), AB (assez bien, bastante bem) e TB

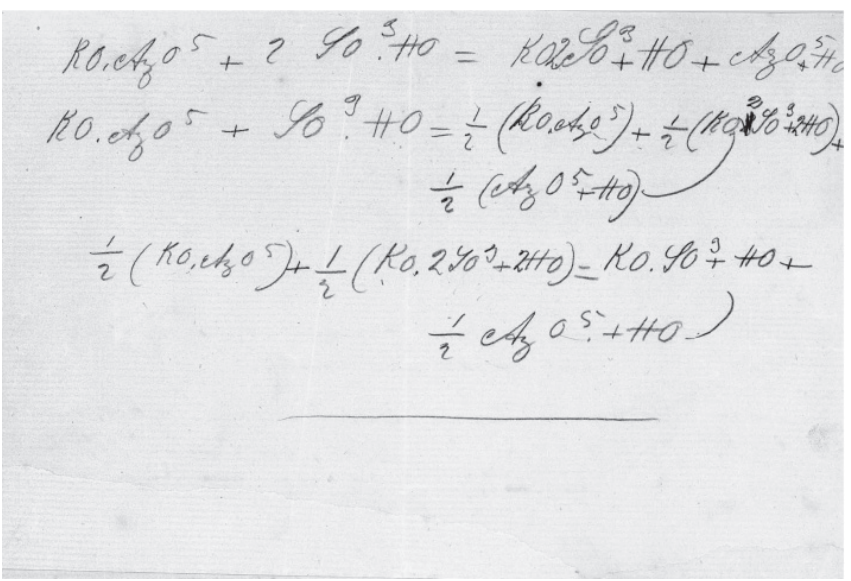

Figura 5. Exercício de balanceamento de equações químicas, manuscrito de autoria de isabel. Arquivo do Grão Pará

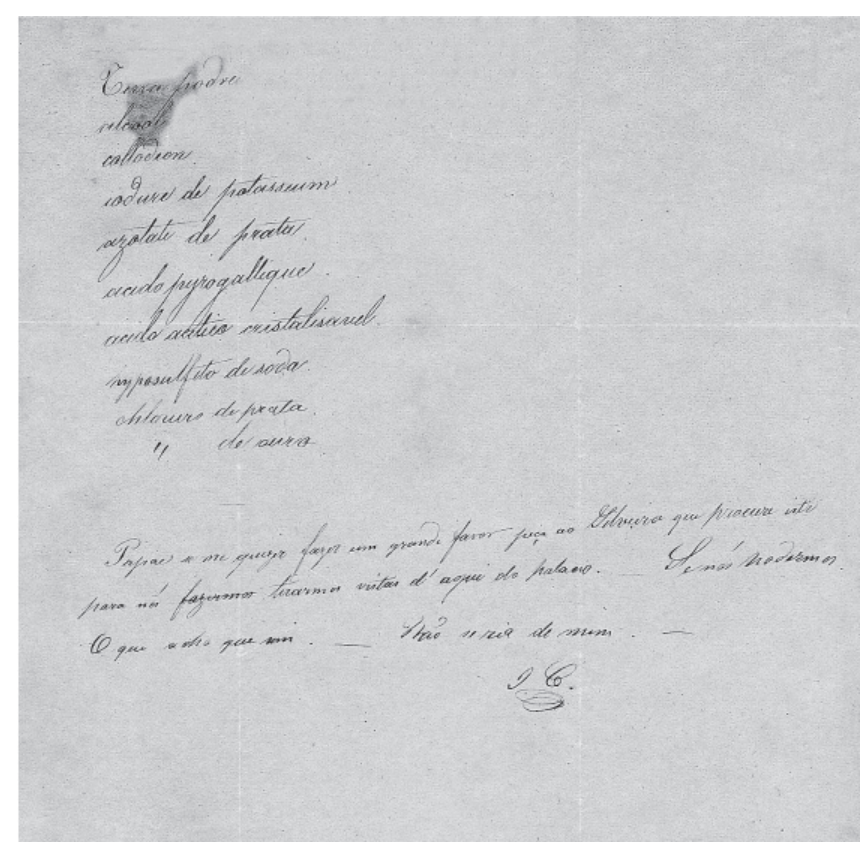

Figura 6. Lista de materiais para revelação fotográfica e bilhete de Isabel para o pai, pedindo-lhe que os mandasse comprar. Arquivo do Grão Pará

(très bien, muito bem). No Boletim de 20/12/1863 há uma menção de Com louvor para o exame de Química de Isabel, a única menção deste tipo encontrada, e também a única escrita em português. A própria Imperatriz Teresa Cristina pôde presenciar e registrar em seu diário (em italiano) o desempenho de suas filhas: Hoje minhas filhas fizeram exame de química - Isabel, muito bem, e Leopoldina, bem. Assistiram-no o Visconde de Sapucaí, Cândido Batista, Dr. Rocha Freire, Santa Maria ${ }^{23}$.

Percebe-se claramente uma diferença entre as duas irmãs, mesmo que a documentação a respeito de Leopoldina seja mais escassa que a de Isabel. Esta era muito mais aplicada e estudiosa que sua irmã caçula. O Professor Francisco Crispiniano Valdetaro, em nota de 22 de abril de 1858, em que listava o que sua pupila Leopoldina, então com 10 anos, deveria fazer como dever de casa, escreve: NB. A sra. P. D. Leopoldina deve dar a lição de versos de cor que não trouxe para hoje, como lhe tinha sido recomendado, tendo dado só a que não soube no dia 15, a semana passada 22 . Presume-se que a nota tenha chegado até o imperador, para as providências cabíveis. 
Freqüentemente, como se lê nos documentos, o próprio D. Pedro II se encarregava de tomar as lições às filhas.

Numa folha solta com a data de 28 de novembro de 1862 Isabel, aos 16 anos, escrevia (ou copiava, não se pode precisar) um texto que mencionava uma nova ideologia nascida havia poucos anos na Europa:

\section{Bom Uso das Riquezas}

Ricos da terra que ela julga felizes e que talvez sois desgraçados, porque receais vós que o comunismo venha a estabelecer-se e a roubar-vos as vossas riquezas? Fazei delas o uso que deveis fazer, $e$ não tereis nada a recear nem para este mundo das ilusões, nem para o outro das realidades ${ }^{22}$.

Os textos tratando de Química encontrados no acervo do Arquivo tratam apenas de Química Inorgânica, não havendo nada de Química Orgânica, o ramo da Química que havia desabrochado com grande força e se encontrava em franco desenvolvimento na Europa. Nos assuntos tratados, os textos refletem fielmente a ciência da época, que era dominada pelo conceito de equivalente, na ausência de uma distinção clara entre átomo e molécula. Esta distinção só veio a se firmar após o Congresso de Karlsruhe, ocorrido em 1860 na Alemanha, quando o químico italiano Angelo Pavesi distribuiu entre os presentes um texto de Stanislao Cannizzaro, em que este mostrava como a esquecida hipótese de Avogadro poderia muito bem sanar a questão ${ }^{24}$. O alemão Lothar Meyer ficou profundamente impressionado com a forma como os conceitos de Avogadro simplificavam a Química e, a partir de seu famoso livro Die modernen Theorien der Chemie, publicado em 1864 (ano em que terminou a educação formal das princesas brasileiras) e logo traduzido em várias línguas, teve um papel de grande importância na disseminação das novas idéias ${ }^{25}$. A Química ensinada à Isabel, naturalmente, era de um teor anterior a todas essas inovações. Por isso se vê uma interessante Lista de Pesos Equivalentes, também reproduzida nas Notas, em que estão presentes implicitamente as dificuldades da época nas determinações quantitativas. Mais interessante ainda é um exercício em que Isabel se esforçava em aprender a balancear equações químicas segundo as convenções da época. Lembrando que até então a fórmula molecular aceita para a água era $\mathrm{HO}$ e os índices se escreviam acima, e não abaixo dos símbolos dos elementos, como hoje, aqui estão as equações, inicialmente na grafia original e, em seguida, em versão moderna.

Equações originais ${ }^{22}$ :

$$
\begin{aligned}
& \text { 1) } \mathrm{KO} \cdot \mathrm{AzO} \mathrm{O}^{5}+2 \mathrm{SO}^{3} \cdot \mathrm{HO}=\mathrm{KO} \cdot 2 \mathrm{SO}^{3}+\mathrm{HO}+\mathrm{AzO}^{5}+\mathrm{HO} \\
& \text { 2) } \mathrm{KO} \cdot \mathrm{AzO}^{5}+\mathrm{SO}^{3} \cdot \mathrm{HO}=1 / 2\left(\mathrm{KO}^{\mathrm{AzO}} \mathrm{O}^{5}\right)+1 / 2\left(\mathrm{KO} \cdot 2 \mathrm{SO}^{3}+2 \mathrm{HO}\right)+ \\
& 1 / 2\left(\mathrm{AzO}^{5}+\mathrm{HO}\right)
\end{aligned}
$$$$
\text { 3) } 1 / 2\left(\mathrm{KO} \cdot \mathrm{AzO}^{5}\right)+1 / 2\left(\mathrm{KO} \cdot 2 \mathrm{SO}^{3}+2 \mathrm{HO}\right)=\mathrm{KO} \cdot \mathrm{SO}^{3}+\mathrm{HO}+
$$$$
1 / 2 \mathrm{AzO}^{5}+\mathrm{HO}
$$

As três equações, em versão moderna (não balanceada), dizem respeito à mesma reação química, que é a produção de ácido nítrico a partir da ação do ácido sulfúrico sobre o nitrato de potássio:

$$
\mathrm{KNO}_{3}+\mathrm{H}_{2} \mathrm{SO}_{4} \longrightarrow \mathrm{K}_{2} \mathrm{SO}_{4}+\mathrm{HNO}_{3}
$$

É simples verificar que o balanceamento feito por Isabel para a primeira equação está correto, mesmo usando suas fórmulas um tanto estranhas para um químico moderno. Em contrapartida, as outras duas equações, para as quais ela imaginava poder obter coeficientes diferentes pelo uso de estequiometrias diferentes da primeira, acaba- ram por tornarem-se armadilhas em que ela se deixou envolver, errando o balanceamento.

Um dos documentos mais interessantes do conjunto é um caderno de 10 folhas, escritas dos dois lados, parecendo um rascunho, escrito em papel com o timbre TMC, da Imperatriz (Teresa Cristina Maria), com uma caligrafia muito parecida com a de D. Pedro II. Uma análise cuidadosa revelou, contudo, que a letra é da própria Isabel, que, ao escrever rapidamente, tinha uma grafia com os mesmos garranchos do pai. O documento corresponde a um texto de química, escrito como se fosse um manual para principiantes. Ele está a lápis e cheio de rasuras. Isabel ainda o copiou na íntegra, à tinta, com caligrafia primorosa, e ajuntou uma capa que ostenta o título Chimica, e as iniciais I.C. Depois fez resumos do conteúdo em pequenos pedaços de papel cortados a tesoura, parecendo lembretes ou notas para estudo. Este documento é um retrato da química da época, onde se vê estampada a confusão ainda reinante entre os conceitos de átomo e molécula, usados indiferentemente, de forma ambígua e imprecisa.

O documento começa assim: §1.Há duas espécies de fenômenos. Uns são produzidos por propriedades passageiras que os corpos adquirem sem modificar as suas aparências físicas e o seu peso. Estes são do domínio da física. Os outros resultam de uma modificação que se opera na natureza dos corpos em presença, e pela qual obtemos novos produtos. Estes são do domínio da química.

A química é a parte das ciências naturais que trata dos fenômenos que se passam ao contacto dos corpos, quando estes trazem uma completa mudança na constituição destes corpos.

As combinações e decomposições químicas são acompanhadas de fenômenos físicos como eletricidade, calor.

A física e a química ajudam-se mutuamente. (No rascunho estava: A física e a química prestam-se serviços mútuos) ${ }^{22}$.

Seguem-se os vários parágrafos, até um total de 9 , seguidos de pouco mais de 4 páginas de Nomenclatura química, uma página intitulada Notações e fórmulas químicas. Linguagem escrita, e outra com a Divisão dos corpos símplices em metalóides e metais ${ }^{22}$. Apresenta-se a seguir a transcrição de mais alguns trechos.

\$2. Distinção dos corpos em corpos símplices e corpos compostos.

Chamam-se corpos compostos aqueles dos quais podemos extrair várias substâncias diferentes entre elas por suas propriedades e diferentes da substância primitiva.

Chamam-se corpos símplices aqueles que submetidos às diversas reações que podemos produzir hoje em nossos laboratórios não foram resolvidos em outras substâncias.

§3. Divisibilidade da matéria.

Os químicos não consideram a divisibilidade da matéria como infinita. Dão o nome de moléculas ou de átomos às partículas excessivamente pequenas e indivisíveis pelos meios mecânicos de que admitem que os corpos são formados.

§6. Afinidade química. A afinidade química é a força que reúne as moléculas símplices constituindo uma molécula de um corpo composto. Para [que] a afinidade química exerça-se livremente precisamos trazer os corpos ao estado líquido ou gasoso. Em muitos casos basta que um dos corpos se ache num destes estados. A temperatura faz variar muito a afinidade química.

§7. Lei das Proporções Múltiplas. Quando dois corpos símplices A e $B$ se combinam, 1 molécula de A se combina com 1, 2, 3, 4,... moléculas de B; ou 2 moléculas de A combinam-se com 1, 2, 3, 4, 5, $7, \ldots$. moléculas de $B$ e assim por diante. Disso conclui-se que nas diversas combinações que uma substância B pode formar com o mesmo peso de uma substância $A$ as quantidades ponderáveis da substância $B$ estarão entre elas em relações racionais $e$ comensuráveis ${ }^{22}$. 
No capítulo Nomenclatura Química encontram-se alguns conceitos bastante interessantes para um leitor moderno, com uma ambivalência entre os conceitos de composto, substância simples e elemento:

Os químicos formam os nomes dos corpos compostos pela combinação dos nomes dos corpos símplices que os constituem.

Os corpos símplices são os únicos que sejam independentes de toda a regra. Os corpos símplices que agora conhecemos são em número de 64.

Os químicos dividem os corpos símplices em metalóides e metais. Os metalóides são em número de 15 e os metais de 49.

Nos corpos compostos distinguimos ácidos, bases, sais, óxidos indiferentes, óxidos singulares e óxidos salinos.

Os sais resultam da combinação dos ácidos (elemento eletronegativo) com as bases (elemento eletropositivo).

Só podemos caracterizar os corpos insolúveis pela maneira com que se comportam sob a influência da pilha, ou atendendo a maneira pela qual se combinam com os corpos ácidos ou básicos sobre a natureza dos quais não duvidamos.

Mais abaixo vêm os conceitos dos diferentes tipos de óxidos:

Dá-se o nome de óxidos às combinações básicas (p.e. óxido de ferro) ou indiferentes (p.e. óxido de carbono) que forma o oxigênio com outros corpos, e o de oxiácidos às combinações ácidas que o oxigênio também pode formar com outros corpos.

Segue-se um longo conjunto de regras de nomenclatura das diversas funções químicas inorgânicas. Após esta parte vêm as regras para escrever as fórmulas químicas, e depois as características dos dois grupos de elementos, ou corpos símplices, que são divididos, como já mencionado anteriormente, em metais e metalóides. Ao final fica a ressalva de quão difícil será decidir se certos corpos devem ser colocados entre os metalóides ou os metais ${ }^{22}$.

Um número bastante razoável de papéis soltos, contendo tabelas, descrições de reações e propriedades de substâncias químicas, etc., também faz parte do acervo cuidadosamente preservado pela família. Um desses papéis diz respeito aos oxicompostos do nitrogênio, e por sua ligação com as equações discutidas anteriormente, será aqui reproduzido:

Combinação do azoto com o oxigênio

$I^{\circ}$ Protóxido de azoto. $-\mathrm{AzO}$

$2^{\circ}$ Deuteróxido de azoto. $-\mathrm{AzO}^{2}$

$3^{\circ}$ Ácido azotoso. $-\mathrm{AzO} \mathrm{O}^{3}$

$4^{\circ}$ Ácido hipoazótico. $-\mathrm{AzO}$

$5^{\circ}$ Ácido azótico. $-\mathrm{AzO} \mathrm{O}^{5}$

Ácido azótico. AzO $\mathrm{O}^{5}$ - Preparamo-lo aquecendo o azotato de potassa ou salpetre com ácido sulfúrico concentrado ${ }^{22}$. Esta é justamente a reação objeto das tentativas de balanceamento mostradas acima. Segue-se um conjunto de propriedades do ácido azótico, ou nítrico.

A educação dada a Isabel e a sua irmã Leopoldina reflete fielmente a personalidade de D. Pedro II, persuadido da importância suprema de uma educação universal e ampla, com um forte teor científico. Um governante, na visão do monarca, deveria estar preparado para entender, mesmo que como observador fora do palco dos acontecimentos, o desenrolar do progresso das ciências e de suas aplicações. Isso era considerado essencial no processo de tomada de decisões. Todavia, Pedro II não se restringia a este aspecto. Ele tinha um gosto especial pelo mundo dos estudos, sobretudo os estudos científicos, chegando a realizar experimentos científicos, escrever trabalhos, tomar parte em reuniões acadêmicas, sendo sócio, por exemplo, da Academia das Ciências de Paris, e corresponder-se extensamente com pessoas ligadas à ciência e à tecnologia, como já se mostrou várias vezes ${ }^{11}$. O que mais surpreende no caso analisado aqui não é o fato de as princesas terem tido a educação que lhes foi proporcionada, mas sim o contraste entre esta e a educação da imensa maioria das mulheres brasileiras da época, mesmo aquelas de origem abastada.

A educação feminina em caráter mais universal e amplo só se logrou efetivamente no Brasil a partir do final do século 19, sobretudo após a implantação da República, com a vinda de inúmeras congregações religiosas para o país, com a finalidade específica de criar um grande número de colégios espalhados de norte a sul do imenso território. À falta de um ensino público universal que atendesse eficazmente às necessidades da população, foi principalmente essa rede de instituições de ensino que supriu as deficiências herdadas do regime anterior.

\section{AGRADECIMENTOS}

$\mathrm{O}$ autor agradece às seguintes pessoas:

D. Pedro Carlos de Orléans e Bragança;

Dra. Maria de Lourdes Parreiras Horta, Diretora do Museu Imperial; Neibe Cristina Machado da Costa, Arquivo do Museu Imperial; Maria de Fátima Moraes Argon, Arquivo do Museu Imperial; Ivan Herzog de Oliveira Junior, Arquivo do Museu Imperial.

\section{REFERÊNCIAS E NOTAS}

1. Lima, L. O.; Estórias da Educação no Brasil: de Pombal a Passarinho, $2^{a}$ ed., s.d., Ed. Brasília: Rio de Janeiro, p. 105-106.

2. Sharpe-Valadares, P. Em ref. 5, p. xxxi.

3. Tobias, J. A.; História da Educação Brasileira, $2^{\mathrm{a}}$ ed., Ed. Juriscredi: São Paulo, s.d., p. 204-206.

4. Duarte, C. L. Em Dicionário de Educadores no Brasil - da Colônia aos Dias Atuais; Fávero, M. L. A.; Britto, J. M., orgs.; 2 2a ed., Ed. UFRJ: Rio de Janeiro, 2002, p. 846-853.

5. Floresta, N.; Opúsculo Humanitário, reedição, Cortez Ed./Fundação José Augusto: São Paulo, 1989, p. 132.

6. Lins, I.; História do Positivismo no Brasil, Brasiliana, Companhia Ed. Nacional: São Paulo, 1964, vol. 322, p. 19.

7. Lacombe, L. L.; Isabel, a Princesa Redentora, Instituto Histórico de Petrópolis: Petrópolis, 1989, p. 42.

8. Carvalho, J. M.; A Construção da Ordem - A Elite Política Imperial, Editora Universidade de Brasília: Brasília, 1980, p. 64-65.

9. Carvalho, J. M.; A Escola de Minas de Ouro Preto - O Peso da Glória, Finep/Companhia Editora Nacional: Rio de Janeiro, 1978, p. 21.

10. Dias, M. O. S.; Aspectos da Ilustração no Brasil, RIHGB 1968, 278, 105.

11. Filgueiras, C. A. L.; Quim. Nova 1988, 11, 210.

12. França, M. F.; As Duas Primeiras Médicas Brasileiras, RIHGB - Anais do Congresso de História do Segundo Reinado, Brasília/Rio de Janeiro, 1984, $2^{\circ}$ vol., p. 7-34.

13. Lyra, H.; História de D. Pedro II, Itatiaia/Edusp: Belo Horizonte, 1977.

14. Em ref. 7, p. 23.

15. Em ref. 7 , p. 33

16. Em ref. 7 , p. 35

17. Em ref. 7 , p. 34 .

18. Em ref. 7 , p. 40

19. Em ref. 7, p. 33

20. Em ref. 7, p. 33-34

21. Em ref. 7, p. 35-39.

22. Pasta Princesa Isabel, Arquivo Grão Pará. Todos os documentos aqui citados pertencem a esta pasta.

23. Em ref. 13, p. 41.

24. Ihde, A. J.; The Development of Modern Chemistry, Harper \& Row: New York, 1970, p. 229.

25. Partington, J. R.; A History of Chemistry, reprint edition, Martino Publishing: New York, 2000, vol. 4, p. 889. 
Nota 1. Horários de aulas e atividades para dois dias de uma semana do ano de 1862, quando Isabel tinha 16 anos. O texto foi deixado no original francês para dar um sabor de como era conduzida a educação da herdeira do trono brasileiro.

\section{Lundi}

De 7 à 7 1 1/2 - Etude de l'histoire de Portugal

De 7 1 $1 / 2$ à 9 - Promenade, déjeuner, visite à Sa Majesté l'Impératrice

De 9 à 10 - Etude de piano

De 10 à 11 - Devoir de Latin. Dictée française

De 11 à midi - Grammaire française. Homonymes

De midi à $2 \frac{1}{2}$ - Dessin

De 2 à 3 - Dîner

De 3 à 4 - Leçon d'allemand

De 4 à 5 - Leçon de Latin avec le $\mathrm{V}^{\mathrm{te}}$.

De 5 à 7 - Promenade, récréation

De 7 à 7 1 $1 / 2$ - Lecture de Barros

De $71 / 2$ à 8 - Souper, prière

De 8 à 91/2 - Etude de l'histoire de France. Faire un devoir d'Anglais

\section{Mardi}

De 7 à 7 1/2 - Etude de vers français

De 7 11/2 à 9 - Promenade, déjeuner, etc.

De 9 à 10 - Devoir d'allemand, devoir de Latin

De 10 à 11 - Leçon d'anglais

De 11 à 11 1/2 - Camões

De 11 1/2 à $2 \mathrm{~h}$ - Leçon de piano, histoire de Portugal et hist. de France avec $\mathrm{M}^{\mathrm{me}}$ de Barral

De 2 à 3 - Dîner et récréation

De 3 à 4 - Leçon de Physique

De 4 à 5 - Botanique appris et récitée

De 5 à 7 - Récréation

De 7 à 7 1 1/2 - Latin avec l'Empereur

De $71 \frac{1}{2}$ à 8 - Souper, prière

De 8 à 9 1 $\frac{1}{2}$ - Tableau du moyen-âge. Lecture française

Nota 2. Exemplo de Boletim Escolar de Isabel (sem data)

\section{Sagesse}

Grammaire Portugaise

Poésie Portugaise

Arithmétique
- B

- Pas du tout

- B

- TB
Lecture Française

Grammaire Française

Homonymes

Vertue

Analyse logique

Cosmographie

ilegível

Mythologie

Tableau

Piano

No Boletim de 20/12/1863 há uma menção Com louvor para o exame de química de Isabel, a única menção deste tipo encontrada, e também a única escrita em português.

Nota 3. Manuscrito de autoria de Isabel, com os pesos equivalentes dos 15 metalóides. Vários aspectos peculiares à Química da época podem ser percebidos, como os símbolos dos elementos iodo, flúor, fósforo e boro, mas principalmente a confusão ainda reinante na determinação de pesos equivalentes ou de pesos atômicos, como o leitor pode aquilatar pelos valores dados, em que o oxigênio ou o hidrogênio eram usados como padrão, em função dos quais os outros elementos tinham seus equivalentes determinados.

Lista de Pesos Equivalentes

Metalóides

Oxigênio $=100$

Oxigênio

Hidrogênio

Azoto

Enxofre

Selênio

Telúrio

Cloro

Bromo

Iodo

Flúor

Fósforo

Arsênico

Carbono

Boro

Silício
- B

- AB

B

- TB

- 1 page

- AB

- M

- TM

- 1 heure 